\title{
Acquired Ichthyosis associated with Type 2 Diabetes Mellitus
}

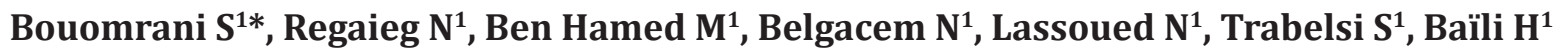

\author{
${ }^{1}$ Department of Internal Medicine, Military Hospital of Gabes, Gabes 6000. Tunisia.
} salembouomrani@yahoo.fr

*Corresponding Author: Dr. Salem Bouomrani, MD, PhD, Department of Internal Medicine, Military Hospital of Gabes, Gabes 6000, Tunisia.

\begin{abstract}
Introduction: Cutaneous lesions are frequent and very polymorphic in diabetic subjects. However, the combination of authentic acquired ichthyosis(AI) with diabetes mellitus (DM) remains exceptional and unusual. We report an original case of AI in type $2 D M$.

Case Report: 55-years-old patient, known diabetic type 2 for 15 years, and treated with oral antidiabetic drugs, was hospitalized for recent significant weight loss (15 kg in two weeks) with appearance of diffuse and very annoyingskin lesions.

Physical examination and skin biopsy confirmed the diagnosis of AI. His diabetes was very unbalanced with HbA1C at 16\%. The advanced investigations had eliminated an underlying autoimmune disease, infection, cancer, and hematological malignancies. After treatment with insulinanalogs in intensive protocol, the evolution was favorable with normalization of the glycemic parameters and progressive disappearance of the cutaneous lesions.

Conclusion: The association of AI with DM remains exceptional and only two cases are found in the literature. Our observation is, to our knowledge, the third reporting this association. The occurrence of AI in a type 2 diabetic may mark the need to introduce insulin.
\end{abstract}

Keywords: Acquired ichthyosis, type 2 diabetes, skin, diabetes mellitus.

\section{INTRODUCTION}

Ichthyosis is classically a neonatal and infantile pathology of hereditary origin with several forms: congenital autosomal recessive ichthyosis (CARI), ichthyosis vulgaris with an autosomal dominant pattern, X-linked ichthyosis, Sjögren-Larsson syndrome (autosomal recessive ichthyosis with mental retardation and progressive spastic paralysis), and Refsun's disease (ichthyosis and progressive neurological dysfunction) [1]. These forms can be schematically classified into two major groups: syndromic and non-syndromicichthyosis [2].

On the other hand, acquired ichthyosis(AI) are far more rare $[1,3,4]$. Their occurrence in adults is exceptional and must always search for an underlying cause: drug intake, infection especially leprosy and HIV, haematological malignancies especially Hodgkin's lymphoma, solid cancer, dysimmune disease such as systemic lupus erythematosus, dermatomyositis, mixed connective tissue disease, sarcoidosis, endocrinopathy with, in particular, hyperparathyroidism, hypothyroidism and hypopituitarism, and bone marrow transplantation [3-5].

The occurrence of AI in diabetics remains exceptional and only two cases have been previously reported in the global medical literature $[3,5]$. Their meanings as well as their mechanisms are still unclear.

We report an original case of AI occurring in a known adult diabetic type 2, and marking the insulinrecurrence.

\section{CASE REPORT}

Tunisian patient aged 55 years, known diabetic type for 15 years and treated with metformin $(1500 \mathrm{mg} / \mathrm{d})$, glimepiride $(3 \mathrm{mg} / \mathrm{d})$ and intestinal alpha-glucosidase inhibitors $(150 \mathrm{mg} / \mathrm{d})$, has just been hospitalized in our service for recent significant weight loss evaluated at $15 \mathrm{~kg}$ in two weeks associated with the appearance of diffuse and very annoyingskin lesions. 
Physical examination found diffuse cutaneous ichthyosis lesions in the abdomen (Fig. 1), back (Fig. 2) and limbs (Fig. 3) with markedpalmoplantar hyperkeratosis. The patient was afebrile, his hemodynamic status was correct, andno adenopathiesor palpable masses were noted. There were no similar cases or history of ichthyosis in the family.

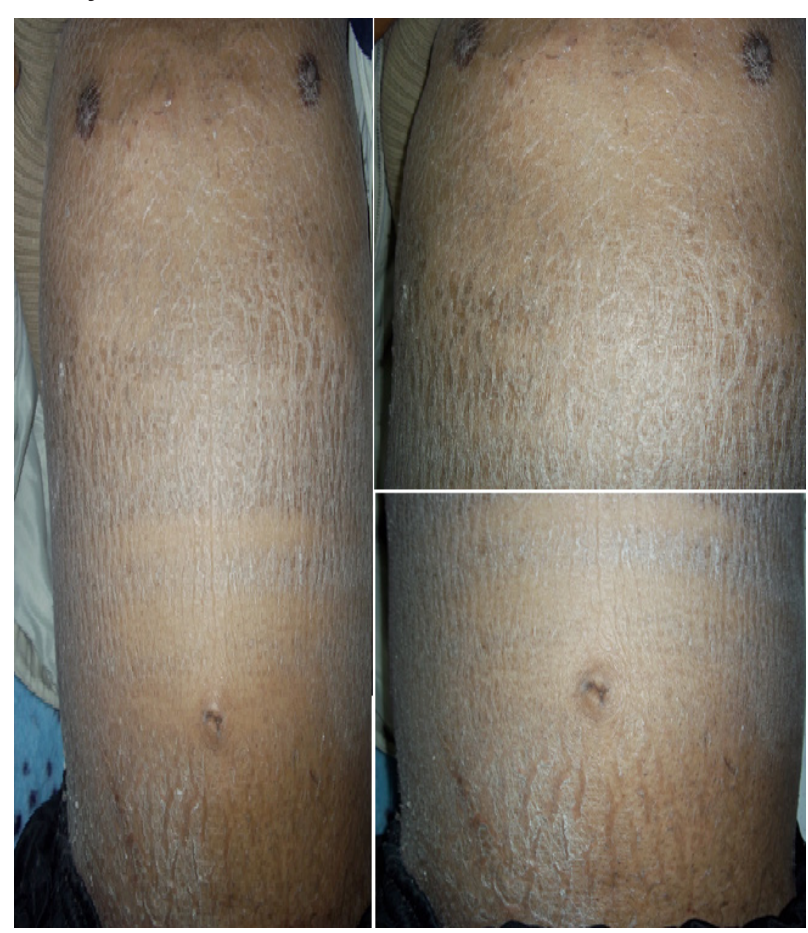

Figure 1. Diffuse ichthyosis in the abdomen.

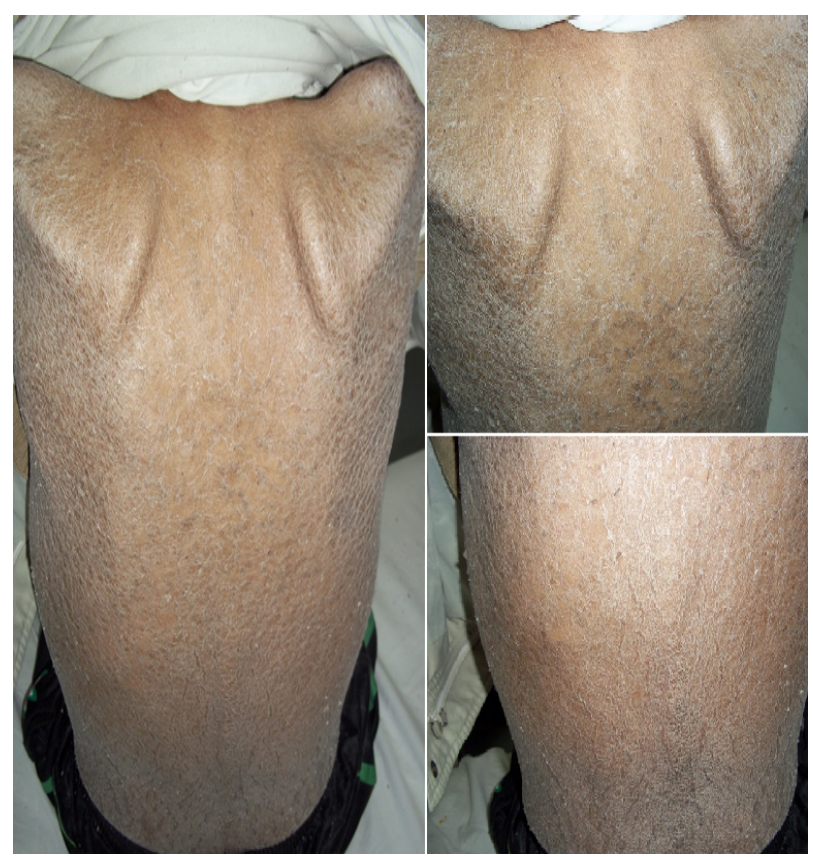

Figure 2. Diffuse ichthyosis in the back.

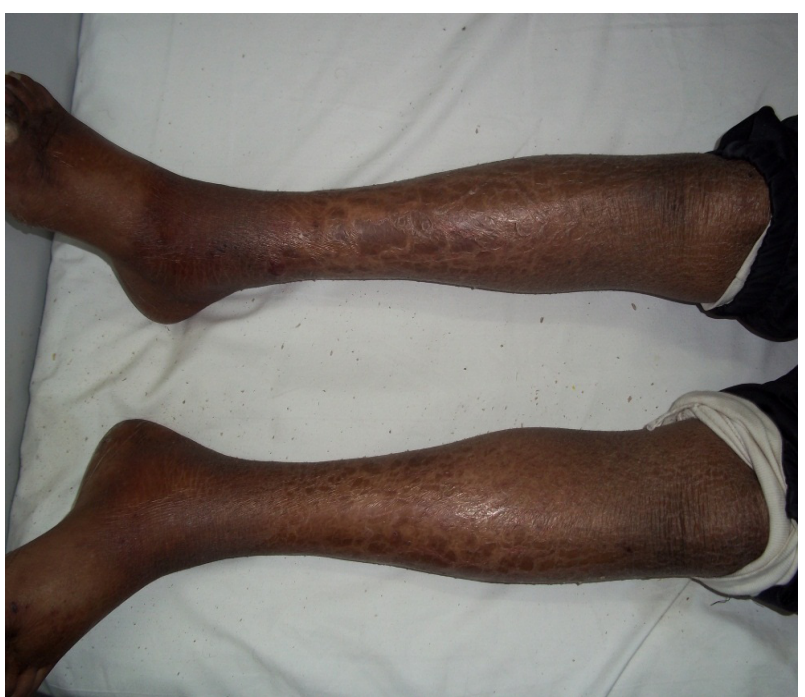

Figure3. Diffuse ichthyosis in both lower limbs.

Biology showed very unbalanced diabetes with fasting glucose at $18 \mathrm{mmol} / \mathrm{l}$, postprandial blood glucose at $28 \mathrm{mmol} / \mathrm{l}$ and $\mathrm{HbA} 1 \mathrm{C}$ at $16 \%$. The rest of the basic biological tests were without abnormalities (complete blood cell count, creatinine, ionogram, calcium, phosphoremia, liver enzymes, alkaline phosphatase, creatininephospho-kinases, lacticdehydrogenases, serum protein electrophoresis, erythrocyte sedimentation rate, C-reactive protein, and 24hproteinuria).

Cutaneous biopsy confirmed the diagnosis of AI. Investigations for an underlying cause were negative, primarily eliminating cancers, hematological malignancies, autoimmune diseases, and infections: anti-nuclear autoantibodies, antisoluble antigenantibodies, HIV serology, TSH, Ft4, t3, thoraco-abdomino-pelvic CT, gastroduodenalfibroscopy, colonoscopy, tumor markers (CA19-9, AFP, CEA, PSA and NSE), immunoelectrophoresis of serum and urinary proteins, myelogram, medullary karyotype, and peripheral lymphocytesimmunophenotyping.

Because of the significant weight loss and marked diabetes imbalance, insulinopenia was evoked. Thus oral antidiabetic drugs were discontinued and insulin therapy started with short-and long-acting insulin analogs (insulin detemir and insulin aspart) according to the basal-bolus protocol. The evolution was favorable with rapid normalization of fast blood glucose and prandial glycemicexcursions. A clear improvement of the cutaneous lesions was also noted under insulin and the complete disappearance was noted after two months of treatment. 


\section{DiscusSION}

Cutaneous manifestations are frequent and varied during both type 1 and type 2 mellitus diabetes (MD). Their frequency was estimated at $68 \%$ in the series of 212 type 1youngdiabetics of Pavlovic MD [6], and at $71 \%$ in the series of 238 type 1 diabetic patients older than 5 years of Yosipovich G [7]. These frequencies were significantly higher in both series compared to healthy controls subjects matched for age and sex: $68 \%$ versus $26.5 \%, \mathrm{p}<0.001$ [6], and $71 \%$ versus $14 \%, \mathrm{p}<0.01$ [7]. The Indian study by Timshina DK also noted a similar frequency in type 2 diabetics [8].

These skin lesions are highly polymorphic and can be of type: ichthyosiformskin changes, sclerodermalike skin changes, diabetic foot, palmo-plantar hyperkeratosis, necrobiosislipoidica, diabetic hands, rubeosisfacies, and keratosis pilaris [6,7]. These lesions are significantly associated with the duration of diabetes and chronic glycemic imbalance $[6,7]$.

Some of these lesions are specific to diabetes such as diabetic foot, diabetic dermatopathy, bullous diabeticorum, sclerodoedemaadultorum of Bushke, and necrobiosislipoidicadiabeticorum, while others are less specific, rarer during diabetes, and their significanceis not yet equivocal: granuloma annulare, vitiligo, achantosisnigricans, and ichthyosiform lesions $[9,10]$.

The so-called "ichthyosiformdematoses" or ichthyosiform skin changes are frequently noted in both type $1[6,7]$ and type 2 diabetics [11] as sporadic or more rarely familial cases associated with insulin resistance [11].

These ichthyosis-like aspects of the skin in diabetics are often the clinical expression of the frequent cutaneous dryness in these patients, and the clinical continuum can be expressed, in growing intensity, as: dry skin feeling, xerosis, and ichthyosiform lesions [12].

Authentic AI associated with DM has been reported only twice:

- First observation of a 14-year-old girl diagnosed with concomitant Alandvery unbalanced type 1 diabetes with $\mathrm{HbA1C}$ at $20.1 \%$ [5],

- Second observation of a 20-year-old man diagnosed with $\mathrm{AI}$ at the same time as type $2 \mathrm{DM}$, with a dramatic change in cutaneous lesions under insulin therapy [3].

The exact mechanism of this lesion during diabetes is not yet well understood, it is incriminated an accumulation in the skin of "advanced glycationend products". This anomaly was objectified by noninvasive autofluorescence in the ZODIAC-9 study [13].

Our observation is the third reporting the association of an AI with DM, and the second with a type 2 diabetes. Its spectacular improvement under insulin marking the stage of insulin-recurrence in our patient, as well as the net improvement under insulin in Sanli $\mathrm{H}$ observation, suggest the direct involvement of diabetic disease in the genesis of this cutaneous lesion [3]; especially the decrease in insulin secretion or insulin resistance [11].

\section{CoNCLUSION}

As rare as it is, $\mathrm{AI}$ in diabetic patient must be known by the clinicians. It may be the first manifestation of the disease or an event that marks the need for the introduction of insulin in an already known type 2 diabetic. Our observation is, to the best of our knowledge, the third reporting an acquired ichthyosis associated with diabetes mellitus.

\section{Abbrivations}

AFP: alpha-fetoprotein,CA 19-9: Carbohydrate Antigen 19-9, CEA: carcinoembryonic antigen, fT4: free tetraiodothyronine, HbA1C: glycated hemoglobin A1c, HIV: human immunodeficiency virus, NSE: neuronespecific enolase, PSA: prostatic specific antigen, t3: triiodothyronine, TSH: Thyroid Stimulating Hormone.

\section{REFERENCES}

[1] DiGiovanna JJ, Robinson-Bostom L. Ichthyosis: etiology, diagnosis, and management. Am J Clin Dermatol. 2003;4(2):81-95.

[2] Oji V, Traupe H. Ichthyosis: clinical manifestations and practical treatment options. Am J ClinDermatol. 2009;10(6):351-64.

[3] Sanli H, Akay BN, Sen BB, Kocak AY, Emral R, Bostanci S. Acquired ichthyosis associated with type 1 diabetes mellitus. Dermatoendocrinol. 2009;1(1):34-6.

[4] Tlacuilo-Parra JA, Guevara-Gutiérrez E, SalazarPáramo M. Acquired ichthyosis associated with systemic lupus erythematosus. Lupus. 2004;13(4):270-3.

[5] Scheinfeld N, Libkind M, Freilich S. New-onset ichthyosis and diabetes in a 14-year-old. PediatrDermatol. 2001;18(6):501-3. 
[6] Pavlović MD, Milenković T, Dinić M, Misović M, Daković D, Todorović S, et al. The prevalence of cutaneous manifestations in young patients with type 1 diabetes. Diabetes Care. 2007;30(8):1964-7.

[7] Yosipovitch G, Hodak E, Vardi P, Shraga I, Karp M, Sprecher E, et al. The prevalence of cutaneous manifestations in IDDM patients and their association with diabetes risk factors and microvascular complications. Diabetes Care. 1998;21(4):506-9.

[8] Timshina DK, Thappa DM, Agrawal A. A clinical study of dermatoses in diabetes to establish its markers. Indian J Dermatol. 2012;57(1):20-5.

[9] Mendes AL, Miot HA, Haddad V Junior. Diabetes mellitus and the skin. An Bras Dermatol. 2017;92(1):8-20.
[10] Bustan RS, Wasim D, Yderstræde KB, Bygum A. Specific skin signs as a cutaneous marker of diabetes mellitus and the prediabetic state - a systematic review. Dan Med J. 2017;64(1). pii: A5316.

[11] Yosipovitch G, Mevorah B, David M, Feinmesser M, Hodak E, Gabay B, et al. Migratory ichthyosiformdermatosis with type 2 diabetes mellitus and insulin resistance. Arch Dermatol. 1999;135(10):1237-42.

[12] Piérard GE, Piérard-Franchimont C, Scheen A. Critical assessment of diabetic xerosis. Expert Opin Med Diagn. 2013;7(2):201-7.

[13] Gerrits EG, Lutgers HL, Kleefstra N, Groenier $\mathrm{KH}$, Smit AJ, Gans RO, et al. Skin advanced glycation end product accumulation is poorly reflected by glycemic control in type 2 diabetic patients (ZODIAC-9). J DiabetesSciTechnol. 2008;2(4):572-7.

Citation: Bouomrani S, Regaieg N, Ben Hamed M, et al. Acquired Ichthyosis associated with Type 2 Diabetes Mellitus. Archives of Diabetes and Endocrine System. 2018; 1(1): 25-28.

Copyright: (C) 2018 Bouomrani S, Regaieg N, Ben Hamed M, et al. This is an open access article distributed under the Creative Commons Attribution License, which permits unrestricted use, distribution, and reproduction in any medium, provided the original work is properly cited. 